\title{
Quality of Life and Clinical-Epidemiologic Profile of Clinical Infirmary Patients
}

\author{
Amanda Travaglia Vitoy ${ }^{1}$, Esther de Paiva Mota ${ }^{1}$, Katarinne Lima Moraes ${ }^{1}$, Jacqueline \\ Andréia Bernardes Leão-Cordeiro ${ }^{2}$, Rogério José de Almeida ${ }^{1}$, Cesar Augusto Sam \\ Tiago Vilanova-Costa ${ }^{3}$ and Antonio Márcio Teodoro Cordeiro Silva ${ }^{1,4^{*}}$
}

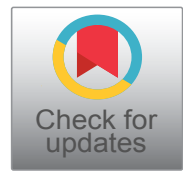

${ }^{1}$ Departamento de Medicina, Escola de Ciências Médicas, Biomédicas e Farmacêuticas, Pontifícia Universidade Católica de Goiás, Goiânia, GO, Brazil

${ }^{2}$ Faculdade de Enfermagem, Universidade Federal de Goiás, Goiânia, GO, Brazil

${ }^{3}$ Associação de Combate ao Câncer em Goiás, Laboratório de Biologia Tumoral, Hospital Araújo Jorge, Goiânia, GO, Brazil ${ }^{4}$ Programa de Pós-Graduação em Ciências Ambientais e Saúde, Pontifícia Universidade Católica de Goiás, Goiânia, GO, Brazil

*Corresponding author: Prof. Dr. Antonio Márcio Teodoro Cordeiro Silva, Departamento de Medicina, Escola de Ciências Médicas, Biomédicas e Farmacêuticas, Programa de Pós-Graduação em Ciências Ambientais e Saúde, Pontifícia Universidade Católica de Goiás, Avenida Universitária 1.440, Setor Universitário, Campus 1, Área 4, Goiânia, Goiás, CEP: 74605010, Brazil, Tel: 55-62-3946-1194

\begin{abstract}
Aims and objectives: To evaluate the quality of life of patients hospitalized in a clinical ward and correlate it with the clinical-epidemiological aspects of these patients.

Background: Traditionally, the evaluation of involvement in patient medical care was grounded in mortality and morbidity rates. Therefore, medical judgement followed clinical, laboratorial and statistic parameters. However, the clear need for a monitoring and evaluation method centered on the patient gave birth to new methods and tools with the aim of measuring individual quality of life subjectively.

Methods: Cross-sectional study, conducted between March and May 2017, in the medical clinic of a hospital in Goiânia, Goiás, Brazil. Two questionnaires were applied in 80 inpatients, one sociodemographic-clinical and SF36. Absolute and relative frequency, central tendency and dispersion were calculated and Student's t tests, ANOVA, Mann-Whitney, Kruskal-Wallis and Pearson's correlation coefficients were used to analyze the data $(\alpha=0.05)$.
\end{abstract}

Results: The main reasons for hospitalization were Chronic Obstructive Pulmonary Disease (COPD), Heart Failure (HF) and Pneumonia. The physical component of SF36 was more affected than mental. The elderly, retirees and low-income patients presented lower scores on functional capacity. The women reported more pain complaints as limiting quality of life. The general state of health was reduced in those who had children and those who were smokers. The physical and social aspects presented a decline in those who had comorbidities, being the worst indexes in COPD patients.

Conclusions: The population pattern of high prevalence of chronic degenerative diseases was confirmed. Elderly, retired or unemployed patients and people with low monthly income have worse quality of life indexes in terms of functional capacity. COPD, a debilitating disease, has affected mental and social health indexes. Concomitantly, smoking, the main risk factor for this comorbidity and many others, was associated with a poorer general health status.

\section{Keywords}

Quality of life, Hospitalization, Chronic disease, Holistic health, Medicine

\section{Introduction}

Defining quality of life is a subject of concern originated from human sciences, namely in the domains of Biology, Humanities and Sociology, as an attempt to consider other parameters other than high life expectancy and mortality reduction [1]. The inherent subjectivity, various approaches and assessment methods of that subject make it difficult to describe in detail [2].

Citation: Vitoy AT, Mota EP, Moraes KL, Leão-Cordeiro JAB, de Almeida RJ, et al. (2019) Quality of Life and Clinical-Epidemiologic Profile of Clinical Infirmary Patients. Int Arch Nurs Health Care 5:130. doi. org/10.23937/2469-5823/1510130

Accepted: August 24, 2019: Published: August 26, 2019

Copyright: (c) 2019 Vitoy AT, et al. This is an open-access article distributed under the terms of the Creative Commons Attribution License, which permits unrestricted use, distribution, and reproduction in any medium, provided the original author and source are credited. 
According to the World Health Organization (WHO), quality of life is "an individual's perception of their position in life in the context of the culture and value systems in which they live and in relation to their goals, expectations, standards and concerns" [3]. The concept covers six domains: physical, psychological, level of dependence, social relations, environmental factors and spiritual aspects [4].

Quality of life indicators change gradually along with historical, cultural, social and technical scientific development of each individual society. Several approaches were taken before the multidimensional concept of quality of life utilized today [1]. The formulation of numerous international scales to evaluate the quality of life of patients under varied clinical conditions is decisive for measuring results of health care interventions. In order for them to be clinically and scientifically reliable, such scales depend on nationwide cultural adaptation and validation in terms of both their application and institution.

As part of the Medical Outcomes Study (MOS), a multisystemic study carried out by Rand Corporation's Health Insurance in the US back in 1992 devised one of those scales - the Short Form 36 Health Survey Questionnaire (SF36) - aiming to help discern how specific components of the American healthcare system influenced patient health reports.

In 1993, Garratt and other researchers in the UK proved the SF36 to be statistically reliable for patients who had received ambulatory care with a response rate of nearly $75 \%$, as well as those with other severe clinical conditions who displayed better overall health status and quality of life [5]. Since its creation, the SF36 has been used to measure patients' perceived health worldwide and reported to be a vastly effective health provision in up to $10 \%$ of all publications prior to the year of 2000 [6].

In Brazil, translation and cultural adaptation to the SF36 started in 1999, upon international regulations and methodology, with a cohort population of 50 patients suffering from rheumatoid arthritis. Its 36-item short form comparative patient-reported survey comprises eight sections: physical functioning, physical role functioning, bodily pain, general health perceptions, vitality, social role functioning, emotional role functioning and mental health. It utilizes a functional score varying from 0 to 100 measured for each section, where zero corresponds to a lower health status and 100 is equivalent to a greater condition [7].

Traditionally, the evaluation of involvement in patient medical care was grounded in mortality and morbidity rates. Therefore, medical judgement followed clinical, laboratorial and statistic parameters. However, the clear need for a monitoring and evaluation method centered on the patient gave birth to new methods and tools with the aim of measuring individual quality of life subjectively [7]. To date, the SF36 is still widely used as a standard tool for health and quality of life evaluation. Due to the very fact that data is generated from self-assessment and self-perception, the use of such tool is commonly recommended for policy and service assessment, research on clinical epidemiology and collaboration for health provisions [8].

Quality of life and health status evaluations performed in intensive care patients with the aid of generic survey tools such as the SF36 are crucial for determining care and attention procedures in this area, as well as the extent to which a certain condition and the patient's sociodemographic profile may affect healthiness. Hospitalization is often followed by a number of side effects caused by specific treatment and the illness acceptance and adaptation period, which entails worry, deep feelings, suffering and limitations imposed to the patient, caregivers and family, together with a significant decrease in physical functioning and changes in the quality of life that are much frequently irreversible.

In the face of such reality, the purpose of this study is to assess the quality of life of intense care patients in a clinical infirmary in correlation with observable aspects of clinical epidemiology.

\section{Methodology}

The present paper delineates an epidemiologic study through analysis, observation and cross-cohort research conducted in the clinical infirmary of Santa Casa de Misericórdia de Goiânia, Goiás, Brazil (SCMG/ $\mathrm{GO})$. Data collection involved two questionnaires: A sociodemographic clinical one and the SF36-v2, applied consecutively to 80 patients admitted between March and May 2017. Patients were at no time required to leave their beds and received all the instructions before signing the Informed Consent Form. Medical records were checked to obtain further data such as diagnostic hypotheses and length of hospital stay. The authorization form for data use was duly signed by the director in charge. The research was approved by both the ethics committee of the education institution (PUC/GO) and the co-participant institution (SCMG/GO).

Following the application of questionnaires and data collection, the SF36 measurements were gathered by taking into consideration each individual section with a 0-100 score range. Only the second question, which relates to the patient general health status within the preceding year, was not used for generating score.

First, we undertook a statistic description of the cohort group, calculating absolute and relative per cent frequencies for categorical variables, as opposed to mean and standard deviation for continuous variables in addition to histograms. Then, the means and confidence intervals of $95 \%$ of all sections and subsections of SF36 for the cohort group subdivided into sociode- 
mographic variables. D'Agostino-Pearson's test for normality was followed by mean comparison in normal distribution scales, Student's t test for two categories and ANOVA for over three categories; in scales without normal distribution, Mann-Whitney's test for two categories and Kruskal-Wallis for over three categories were performed. Tests with a $p$-value equal or inferior to 0.05 were considered statistically significant. Cronbach's alpha was used to calculate data reliability. Finally, Pearson's $r$ was used to find possible correlations between continuous variables and sections or subsections of SF36.

Inclusion criteria: Participants aged $\geq 18$ admitted in the clinical infirmary of SCMG/GO, all of whom able and consenting to answer the questionnaires.

Exclusion criteria: Patients aged $<18$ physically, mentally or socially unable to answer the questionnaires, patients with inaccurate or incomplete diagnosis, patients hospitalized outside the infirmary of SCMG/GO, and patients who did not consent to participate in the group.

\section{Results}

The cohort group had a total of 80 patients, 42 males and 38 females, with a mean age of 65.3 (20 minimum and 93 maximum). The socio-demographic characteristics of the cohort group can be seen on Table 1. We should point out that the majority of patients are retired $(58.8 \%)$ and uneducated $(72.5 \%)$, of

Table 1: Socio-demographic characteristics of the cohort group by sex, Goiânia, Goiás, Brazil, 2017.

\begin{tabular}{|c|c|c|c|c|c|c|}
\hline \multirow{2}{*}{ Variables } & \multicolumn{2}{|c|}{ Females $(n=38)$} & \multicolumn{2}{|c|}{ Males $(n=42)$} & \multicolumn{2}{|c|}{ Total $(n=80)$} \\
\hline & af & rf (\%) & af & $r f(\%)$ & af & $r f(\%)$ \\
\hline \multicolumn{7}{|l|}{ Age } \\
\hline Average (SD) & \multicolumn{2}{|c|}{$66.2(15.9)$} & \multicolumn{2}{|l|}{$64.5(18.9)$} & \multicolumn{2}{|c|}{$65.3(17.5)$} \\
\hline Lowest-Highest & \multicolumn{2}{|l|}{$29-89$} & \multicolumn{2}{|l|}{$20-93$} & \multicolumn{2}{|c|}{$20-93$} \\
\hline \multicolumn{7}{|l|}{ Education } \\
\hline Illiterate & 6 & 15.8 & 8 & 19 & 14 & 17.5 \\
\hline Can read and write & 2 & 5.3 & 6 & 14.3 & 8 & 10 \\
\hline Left Primary School & 18 & 47.4 & 18 & 42.9 & 36 & 45 \\
\hline Finished Primary School & 6 & 15.8 & 7 & 16.7 & 13 & 16.3 \\
\hline Finished Secondary School & 6 & 15.8 & 3 & 7.1 & 9 & 11.3 \\
\hline \multicolumn{7}{|l|}{ Occupation } \\
\hline Employed & 5 & 13.2 & 13 & 31 & 18 & 22.5 \\
\hline Unemployed & 8 & 21.1 & 7 & 16.7 & 15 & 18.8 \\
\hline Retired & 25 & 65.8 & 22 & 52.4 & 47 & 58.8 \\
\hline \multicolumn{7}{|l|}{ Marital Status } \\
\hline Single & 3 & 7.9 & 10 & 23.8 & 13 & 16.3 \\
\hline Wedded/Cohabiting & 17 & 44.7 & 22 & 52.4 & 39 & 48.8 \\
\hline Divorced & 2 & 5.3 & 3 & 7.1 & 5 & 6.3 \\
\hline Widowed & 16 & 42.1 & 7 & 16.7 & 23 & 28.8 \\
\hline \multicolumn{7}{|l|}{ Monthly Income } \\
\hline Up to $1 \mathrm{MW}$ & 21 & 55.3 & 26 & 61.9 & 47 & 58.8 \\
\hline Up to $2 \mathrm{MW}$ & 12 & 31.6 & 12 & 28.6 & 24 & 30 \\
\hline Over $2 \mathrm{MW}$ & 5 & 13.2 & 4 & 9.5 & 9 & 11.3 \\
\hline \multicolumn{7}{|l|}{ Children } \\
\hline No & 2 & 5.3 & 4 & 9.5 & 6 & 7.5 \\
\hline Yes & 36 & 94.7 & 38 & 90.5 & 74 & 92.5 \\
\hline How many? Average (SD) & \multicolumn{2}{|l|}{$3.2(1.0)$} & \multicolumn{2}{|l|}{$3.0(1.2)$} & \multicolumn{2}{|c|}{$3.1(1.1)$} \\
\hline \multicolumn{7}{|l|}{ Chaperone } \\
\hline No & 8 & 21.1 & 12 & 28.6 & 20 & 25 \\
\hline Yes & 30 & 78.9 & 30 & 71.4 & 60 & 75 \\
\hline \multicolumn{7}{|l|}{ Admission Period } \\
\hline Days - Average (SD) & \multicolumn{2}{|l|}{$4.3(3.0)$} & \multicolumn{2}{|l|}{$4.6(4.8)$} & \multicolumn{2}{|c|}{$4.4(4.0)$} \\
\hline \multicolumn{7}{|l|}{ Alcohol } \\
\hline No & 28 & 73.7 & 7 & 16.7 & 35 & 43.8 \\
\hline
\end{tabular}




\begin{tabular}{|c|c|c|c|c|c|c|}
\hline Yes & 10 & 26.3 & 35 & 83.3 & 45 & 56.3 \\
\hline \multicolumn{7}{|l|}{ Tobacco } \\
\hline No & 23 & 60.5 & 10 & 23.8 & 33 & 41.3 \\
\hline Yes & 15 & 39.5 & 32 & 76.2 & 47 & 58.8 \\
\hline \multicolumn{7}{|l|}{ Tobacco use } \\
\hline Packs/Year - Average (SD) & \multicolumn{2}{|c|}{$38.7(25.9)$} & \multicolumn{2}{|c|}{$48.2(42.4)$} & \multicolumn{2}{|c|}{$45.1(37.9)$} \\
\hline
\end{tabular}

Key: MW: Minimum Wage (1 MW = R\$ 937,00); SD: Standard Deviation; af: Absolute Frequency; rf (\%): Percent Relative Frequency.

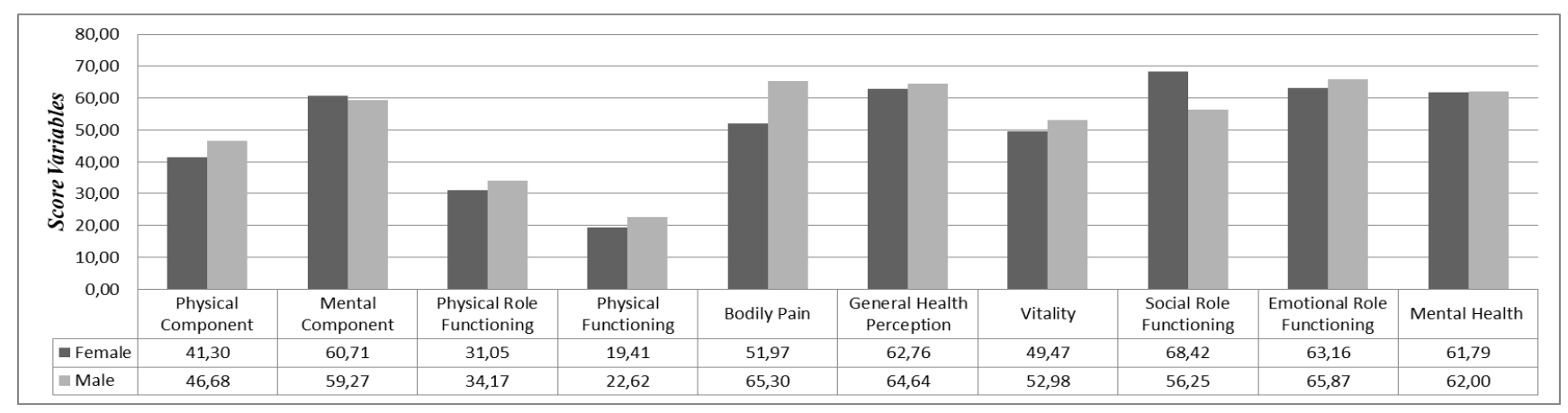

Figure 1: Average scores of males and females in sections and subsections of SF36.

which only $27.6 \%$ finished primary school. The marital status and family structure components included $48.8 \%$ of wedded participants, $28.8 \%$ widowed ( 16 females and 7 males), and a total of $92.5 \%$ parents. The family income component revealed a predominance of lower class participants, $58.8 \%$ of whom earning a meager minimum income and $30 \%$ two times the minimum wage.

The average admission time was 4.4 days, calculated at the time of questionnaire surveys. The main reasons for admission were earlier cardiopulmonary complications such as Chronic Obstructive Pulmonary Disease (COPD), Heart Failure (HF) as well as casual or causal pneumonia. $27.5 \%$ of diagnosis involved other conditions such as pyelonephritis, cirrhosis, erysipelas, lupus, arrhythmogenic syndromes and dengue fever. In the majority, patients suffered from chronic diseases like Systemic Hypertension (56.3\%), Diabetes Mellitus (28.8\%) COPD (27.5\%) and HF (27.5\%). As for lifestyle, $56.3 \%$ of patients consumed alcohol ( 35 males and 10 females) and $58.8 \%$ used tobacco ( 32 males and 15 females). It is worth mentioning that the average number of cigarette packs consumed per year was 45.1.

The average scores of SF36 sections and subsections are displayed in Figure 1. The physical component was more affected than the mental component, in the same way women were more affected than men (respectively 41.3 and 46.68 , with no statistical importance for the evaluation by gender). Among all patients, the physical role functioning (21.09) and physical functioning (32.69) were the most affected sections, while the emotional role functioning (64.58), social role functioning (62.03) and general health perceptions (63.75) sections were the least affected.
The analysis of sections and subsections of SF36 clinical-epidemiologic variables (Table 2) shows statistic evidence $(p<0.05)$ that the elderly, unemployed, retired and underprivileged patients had lower scores in physical functioning. In the gender criteria, bodily pain affecting the quality of life was a complaint primarily among women. Parents showed lower values in general health perception and vitality. Physical role functioning and social role functioning were lower in patients with comorbidities, especially among those suffering from COPD (respectively 9.66 and 53.41). The hypothesis of admission for COPD patients revealed lower scores for mental health. The presence of chaperones altered quality of life scores significantly and was associated with lower scores in the physical components and the emotional role functioning. Marital status, education and alcohol were not found to be factors of considerable influence on patient quality of life.

\section{Discussion}

Two facts stand out from the analysis of patients' epidemiologic profiles admitted at the clinical infirmary of SCMG/GO: The mean age of 65.3 and a preponderance of retirees, which reflect an observable reality across the country that has already been discussed by other published works. According to Loyola Filho, et al. [9], hospitalization rate among patients aged $\geq 60$ was two times the rate of patients in the 20-59 age bracket. Among elderly patients, hospitalization rate increased with age.

Another important factor in the cohort group is the high occurrence of diabetes mellitus and systemic hypertension, two non-communicable chronic diseases that lead to or result in $63 \%$ of death causes worldwide 
Table 2: Sections and Subsections of SF36 in correlation with the clinical-epidemiologic profile variables, Goiânia, Goiás, Brazil, 2017.

\begin{tabular}{|c|c|c|c|c|c|c|c|c|c|c|c|c|}
\hline \multirow[t]{2}{*}{ Variables } & \multicolumn{2}{|c|}{ Total $(n=80)$} & \multicolumn{10}{|c|}{ Sections and subsections of SF36 } \\
\hline & af & $r f(\%)$ & PF & PRF & Pain & GHP & Vitality & SRF & ERF & MH & PC & MC \\
\hline \multicolumn{13}{|l|}{ Age } \\
\hline$<60$ & 23 & 28.8 & 40.87 & 25.54 & 54.24 & 59.78 & 50.43 & 57.61 & 69.57 & 57.39 & 45.11 & 58.75 \\
\hline$\geq 60$ & 57 & 71.3 & 29.39 & 19.30 & 60.88 & 65.35 & 51.67 & 63.82 & 62.57 & 63.72 & 43.73 & 60.44 \\
\hline$p$-value & & & $0.039^{*}$ & 0.144 & 0.209 & 0.108 & 0.385 & 0.254 & 0.222 & 0.061 & 0.372 & 0.342 \\
\hline \multicolumn{13}{|l|}{ Gender } \\
\hline Females & 38 & 47.5 & 31.05 & 19.41 & 51.97 & 62.76 & 49.47 & 68.42 & 63.16 & 61.79 & 41.30 & 60.71 \\
\hline Males & 42 & 52.5 & 34.17 & 22.62 & 65.30 & 64.64 & 52.98 & 56.25 & 65.87 & 62 & 46.68 & 59.28 \\
\hline$p$-value & & & 0.301 & 0.274 & $0.035^{\star}$ & 0.323 & 0.179 & 0.075 & 0.372 & 0.305 & 0.078 & 0.352 \\
\hline \multicolumn{13}{|l|}{ Education } \\
\hline Uneducated & 22 & 27.5 & 30.23 & 16.48 & 61.70 & 57.50 & 47.50 & 62.50 & 57.20 & 58.91 & 41.48 & 56.53 \\
\hline Finished Primary School & 49 & 61.3 & 31.53 & 22.58 & 57.30 & 65.20 & 52.45 & 61.73 & 65.48 & 63.18 & 44.15 & 60.71 \\
\hline $\begin{array}{l}\text { Finished Secondary } \\
\text { School }\end{array}$ & 9 & 11.3 & 45.00 & 24.31 & 61.39 & 71.11 & 54.44 & 62.50 & 77.78 & 62.22 & 50.45 & 64.24 \\
\hline$p$-value & & & 0.331 & 0.561 & 0.853 & 0.107 & 0.553 & 0.996 & 0.360 & 0.612 & 0.585 & 0.547 \\
\hline \multicolumn{13}{|l|}{ Occupation } \\
\hline Employed & 18 & 22.5 & 46.39 & 27.43 & 60.97 & 67.50 & 54.72 & 59.72 & 79.63 & 67.11 & 50.57 & 65.30 \\
\hline Unemployed & 15 & 18.8 & 35.33 & 28.33 & 55 & 62.33 & 54.33 & 65.83 & 61.11 & 57.87 & 45.25 & 59.79 \\
\hline Retired & 47 & 58.8 & 26.60 & 16.36 & 59.47 & 62.77 & 49.04 & 61.70 & 59.93 & 61.19 & 41.30 & 57.97 \\
\hline$p$-value & & & $0.021^{*}$ & 0.099 & 0.866 & 0.618 & 0.362 & 0.896 & 0.140 & 0.252 & 0.134 & 0.287 \\
\hline \multicolumn{13}{|l|}{ Marital Status } \\
\hline Single & 13 & 16.3 & 40 & 25.96 & 71.15 & 70.77 & 60 & 62.50 & 69.87 & 65.54 & 51.97 & 64.48 \\
\hline Wedded/Cohabiting & 39 & 48.8 & 37.05 & 22.28 & 53.08 & 60.90 & 50.90 & 61.22 & 64.32 & 59.18 & 43.33 & 58.90 \\
\hline Divorced/Widowed & 28 & 35 & 23.21 & 17.19 & 61.52 & 64.46 & 47.86 & 62.95 & 62.50 & 64 & 41.60 & 59.33 \\
\hline$p$-value & & & 0.078 & 0.504 & 0.203 & 0.228 & 0.096 & 0.983 & 0.839 & 0.349 & 0.172 & 0.574 \\
\hline \multicolumn{13}{|l|}{ Monthly Income } \\
\hline Up to $1 \mathrm{MW}$ & 47 & 58.8 & 28.62 & 20.88 & 61.91 & 61.81 & 49.79 & 66.22 & 62.59 & 60.34 & 43.31 & 59.74 \\
\hline $2 \mathrm{MW}$ or more & 33 & 41.3 & 38.48 & 21.40 & 54.77 & 66.52 & 53.48 & 56.06 & 67.42 & 64.12 & 45.30 & 60.27 \\
\hline$p$-value & & & $0.050^{*}$ & 0.462 & 0.172 & 0.128 & 0.169 & 0.119 & 0.283 & 0.159 & 0.304 & 0.444 \\
\hline \multicolumn{13}{|l|}{ Children } \\
\hline No & 6 & 7.5 & 35 & 29.17 & 70.83 & 77.50 & 70.83 & 56.25 & 66.67 & 71.33 & 53.13 & 66.27 \\
\hline Yes & 74 & 92.5 & 32.50 & 20.44 & 58.01 & 62.64 & 49.73 & 62.50 & 64.41 & 61.14 & 43.40 & 59.45 \\
\hline$p$-value & & & 0.169 & 0.077 & 0.181 & $0.026^{*}$ & $0.001^{*}$ & 0.349 & 0.443 & 0.074 & 0.089 & 0.169 \\
\hline \multicolumn{13}{|l|}{ Chaperone } \\
\hline No & 20 & 25 & 44.75 & 31.56 & 55.63 & 62.50 & 50 & 68.75 & 77.92 & 59.20 & 48.61 & 63.97 \\
\hline Yes & 60 & 75 & 28.67 & 17.60 & 60.08 & 64.17 & 51.75 & 59.79 & 60.14 & 62.80 & 42.63 & 58.62 \\
\hline$p$-value & & & $0.009^{*}$ & $0.011^{*}$ & 0.302 & 0.362 & 0.345 & 0.180 & $0.030^{*}$ & 0.201 & 0.086 & 0.108 \\
\hline \multicolumn{13}{|l|}{ Alcohol } \\
\hline No & 35 & 43.8 & 31.43 & 20.36 & 58.07 & 64.86 & 50 & 63.93 & 68.33 & 65.14 & 43.68 & 61.85 \\
\hline Yes & 45 & 56.3 & 33.67 & 21.67 & 59.67 & 62.89 & 52.33 & 60.56 & 61.67 & 59.38 & 44.47 & 58.48 \\
\hline$p$-value & & & 0.355 & 0.404 & 0.416 & 0.316 & 0.272 & 0.347 & 0.212 & 0.061 & 0.418 & 0.187 \\
\hline \multicolumn{13}{|l|}{ Tobacco } \\
\hline No & 33 & 41.3 & 34.55 & 22.92 & 60.53 & 68.03 & 53.48 & 64.02 & 68.94 & 65.58 & 46.51 & 63.01 \\
\hline Yes & 47 & 58.8 & 31.38 & 19.81 & 57.87 & 60.74 & 49.79 & 60.64 & 61.52 & 59.32 & 42.46 & 57.82 \\
\hline$p$-value & & & 0.301 & 0.284 & 0.363 & $0.038^{*}$ & 0.169 & 0.348 & 0.189 & $0.048^{*}$ & 0.147 & 0.086 \\
\hline \multicolumn{13}{|l|}{ Chronic Diseases } \\
\hline Systemic hypertension & 45 & 56.3 & 30.22 & 19.17 & 54.56 & 63 & 50.22 & 75 & 60.19 & 62.49 & 41.74 & 61.97 \\
\hline
\end{tabular}




\begin{tabular}{|c|c|c|c|c|c|c|c|c|c|c|c|c|}
\hline Diabetes mellitus & 23 & 28.8 & 36.30 & 27.17 & 53.59 & 65.22 & 50.65 & 69.02 & 57.61 & 61.91 & 45.57 & 59.80 \\
\hline COPD & 22 & 27.5 & 21.14 & 9.66 & 63.64 & 62.27 & 52.73 & 53.41 & 69.70 & 61.64 & 39.18 & 59.37 \\
\hline HF & 22 & 27.5 & 22.95 & 11.36 & 69.32 & 62.95 & 52.05 & 53.41 & 66.67 & 66.55 & 41.65 & 59.67 \\
\hline Others & 37 & 46.3 & 27.57 & 17.40 & 64.46 & 65.68 & 53.78 & 49.32 & 70.27 & 65.30 & 43.78 & 59.67 \\
\hline$p$-value & & & 0.154 & $0.048^{*}$ & 0.276 & 0.931 & 0.895 & $0.012^{*}$ & 0.608 & 0.739 & 0.681 & 0.948 \\
\hline \multicolumn{13}{|l|}{ Hypothese } \\
\hline Pneumonia & 33 & 41.3 & 32.58 & 21.21 & 55.91 & 62.88 & 50.30 & 71.97 & 58.33 & 61.94 & 43.15 & 60.64 \\
\hline HF & 17 & 21.3 & 38.82 & 21.69 & 73.68 & 70 & 59.41 & 66.91 & 79.90 & 70.35 & 51.05 & 69.15 \\
\hline COPD & 10 & 12.5 & 13.50 & 5.63 & 61 & 58 & 45 & 37.50 & 74.17 & 62 & 34.53 & 54.67 \\
\hline Others & 22 & 27.5 & 35 & 25.57 & 51.93 & 64.32 & 50 & 52.84 & 60.99 & 57.09 & 44.21 & 55.23 \\
\hline$p$-value & & & 0.090 & 0.166 & 0.195 & 0.383 & 0.126 & $0.042^{*}$ & 0.189 & 0.100 & 0.096 & $0.042^{*}$ \\
\hline
\end{tabular}

Key: MW: Minimum Wage (1 MW = R\$ 937,00); af: Absolute Frequency; rf (\%): Percent Relative Frequency; HF: Heart Failure; COPD: Chronic Obstructive Pulmonary Disease; PF: Physical Functioning; PRF: Physical Role Functioning; GHP: General Health Perception; SRF: Social Role Functioning; ERF: Emotional Role Functioning; MH: Mental Health; PC: Physical Components; MC: Mental Components.

[10]. In 2013, Brazil ranked $4^{\text {th }}$ in the list of countries by diabetes prevalence, with 11.9 million cases among adults in the 20-79 age bracket [11]. As for hypertension, little population-based research has been done, but estimates of the self-report National Health Survey conducted in the same year indicate a $21.4 \%$ rate countrywide [10]. In the cohort group, $60 \%$ were tobacco users (45.1 packs/year) despite efforts made through awareness raising initiatives [12].

Concerning the reasons for admission, cardiorespiratory-related causes like HF and COPD prevailed over casual and causal pneumonia. In 2012, according to the Brazilian Information Department of the Unified Health System (DATASUS) a total of 238 thousand admissions due to HF were registered [13]. COPD corresponds to a large portion of the number of healthcare expenditures due to the high number of admissions and ensuing aggravations, leading to and corroborating quality of life losses and higher chances of mortality [14]. Community-acquired pneumonia measured rates in patients aged $>60$ were 25-35 cases per 1000 inhabitants/year and represents a frequent reason for emergency care admission [15].

In a recent study in Virginia, US, Mihailoff, et al. [15] observed that patients with chronic conditions corresponded to higher readmission rates (30 days after discharge) and therefore worsening financial effects, most of them related to COPD, HF and pneumonia [16]. Given this scenario, New Zealand was able to decrease admission rate and increase chronic patients' quality of life after the implementation of special service dial numbers targeted at patients suffering from diabetes mellitus, heart failure and chronic obstructive pulmonary disease.

By analyzing the correlation between SF36 parameters and the clinical-epidemiological profile variables, low quality of life associated with physical functioning among elderly patients appears to have hastened aging and aggravated chronic-degenerative diseases that led to hospitalizations in that age bracket [17]. In Korea, a Senior-Friendly Hospital was established to ensure medical care, attention and quality of life for aggrieved aged patients whose hospitalization brought about physical or mental functioning limitations [18]. Multidiscipline and patient-centered support has a profoundly positive impact on post-admission quality of life [19].

The main complaint among women as a detrimental factor to quality of life was bodily pain. A study carried out in Denmark has pinpointed women, blighted area dwellers, underprivileged, underpaid or abandoned citizens are the most afflicted with chronic pain [20]. The pain/low quality of life correlation was referred to in the same study, with women suffering from chronic pain also reporting increased emotional stress, depression, personality disorders and weak social skills. Chronic pain is a major public health concern with immediate and individual consequences that for the most part involve the family, caregivers and the general society. All aspects of quality of life, including physical health, mental health and social role functioning are compromised under such condition [20]. Alleviation oftentimes requires multidiscipline approaches coupled with cognitive therapies [21].

Unemployed and retired patients showed lower scores for physical functioning when compared to patients who worked regularly. This correlates directly with the study in Southern Korea about the importance of work for non-manual labors as a protective factor against depression and suicidal ideation [22].

Patients with low monthly income scored lower in the physical role functioning dimension of quality of life when compared to those earning over two minimum wages. Researches conducted by the National Household Sample Survey (PNAD) have indicated that the physical role functioning of aged citizens is strongly influenced by per capita household income [23]. Compared to citizens in good health condition, underprivi- 
leged persons are more prone to health status limitations, chronic diseases and behavior risk factors, which may explain functional limitations and their impact on the quality of life [24].

A strong correlation identified was that of tobacco use and lower scores in the dimension of mental health. This fact is already known and also due to smoking habits being three times more frequent among people with some degree of mental disorder than non-smokers [25]. Tobacco use itself is classified by the World Health Organization as a mental disorder. Moreover, tobacco users, had the lowest scores in general health self-perception. Scientific literature published internationally validates that lifestyle, physical exercise, tobacco and alcohol use exert considerable influence on the way individuals perceive their health [26].

The decline of physical functioning along with emotional and social role functioning for patients with chaperones puts forward the hypothesis that these quality of life dimensions had already been compromised prior to admission, which explains the necessity of a guardian. The predominance of aged patients in the cohort group validates this hypothesis in agreement with art. 16 of the Statute of Senior Citizens (Estatuto do Idoso, Lei 10.741/03). This analysis highlights the relevance of pinpointing quality of life factors before, during and after admission. Research conducted in different clinical centers in the US has called the attention to pre-hospital quality of life being a strong indicator of welfare and restfulness post-admission for patients in various health statuses. Although admission is related to higher chances of quality of life lessening after discharge, the overall proportion of this reduction is low [27].

Hospitalization due to COPD aggravation was a determining factor of low mental health scores, as seen in a study undertaken in Singapore with COPD patients in contrast with COPD-free individuals. The former reported close association between stressing lifestyle and depression and resultant low quality of life [28]. COPD is a chronic debilitating disease related with physical struggles and emotional disorder, which influence directly on the social role functioning and represents a comorbidity of great impact on the quality of life of individuals and their social life.

The demographic transition that took place in Brazil paired with the consequent decrease in fertility and birth rates and progressive elderly population growth contributed to increasing chronic-degenerative diseases, which today correspond to the highest morbimortality rates and over $70 \%$ of health expenditures. Identifying the factors that hasten the natural process of physical role functioning loss with aging is fundamental for adopting more effective health strategies in addition to the implementation of public policies in favor of elderly physical role functioning maintenance [29].

\section{Conclusions}

Data analyses have confirmed the high incidence of chronic-degenerative diseases such as systemic hypertension, diabetes mellitus, chronic obstructive pulmonary disease and heart failure. Aged patients, retirees, the unemployed and underprivileged showed the worst rates of quality of life in the physical role functioning factor. COPD and its debilitating elements has affected negatively the mental and social health. Tobacco use, as a concomitant risk factor of this and many other comorbidities, was associated with worse general health statuses. The social relevance of the present study lies in the evaluation of patient quality of life, especially those suffering from chronic diseases, and the proposal of attention and care practices to prevent and control illnesses, as well as the environmental risk factors linked with physical role functioning reduction and limitations in the quality of life.

\section{References}

1. Pereira ÉF, Teixeira CS, Santos A (2012) Quality of life: Approaches, concepts and assessment. Rev Bras Educ Fís Esporte 26: 241-250.

2. Silva JV, Baptista MN (2016) Vitor quality of life scale for the elderly: Evidence of validity and reliability. Springerplus 5: 1450.

3. (1995) The World Health Organization Quality of Life assessment (WHOQOL): Position paper from the World Health Organization. Soc Sci Med 41: 1403-1409.

4. Kumar SP (2012) Reporting of "quality of life": A systematic review and quantitative analysis of research publications in palliative care journals. Indian J Palliat Care 18: 59-67.

5. Garratt AM, Ruta DA, Abdalla MI, Buckingham JK, Russell IT (1993) The SF 36 health survey questionnaire: An outcome measure suitable for routine use within the NHS? BMJ 306: 1440-1444.

6. Burholt V, Nash P (2017) Short Form 36 (SF-36) Health Survey Questionnaire: Normative data for Wales. J Public Health (Oxf) 33: 587-603.

7. Ciconelli RM, Ferraz MB, Santos W, Meinão I, Quaresma MR (1999) Tradução para a língua portuguesa e validação do questionário genérico de avaliação de qualidade de vida SF-36 (Brasil SF-36). Rev Bras Reumatol Sociedade Brasileira de Reumatologia 39: 143-150.

8. Unalan D, Soyuer F, Ozturk A, Mistik S (2008) Comparison of SF-36 and WHOQOL-100 in patients with stroke. Neurol India 56: 426-432.

9. Malta DC, Bernal RTI, Andrade SSCA, Silva MMAD, Velasquez-Melendez G (2017) Prevalence of and factors associated with self-reported high blood pressure in Brazilian adults. Rev Saude Publica 51.

10. Sorio Flor L, Rodrigues Campos M (2017) The prevalence of diabetes mellitus and its associated factors in the Brazilian adult population: Evidence from a population-based survey. Rev Bras Epidemiol 20: 16-29.

11. Krosnick JA, Malhotra N, Mo CH, Bruera EF, Chang L, et al. (2017) Perceptions of health risks of cigarette smoking: A new measure reveals widespread misunderstanding. PLoS One 12: e0182063. 
12. Poffo MR, Vieira De Assis A, Fracasso M, Miguel O, Filho $L$ (2017) Profile of patients hospitalized for heart failure in tertiary care hospital. Int J Cardiovasc Sci 30: 189-198.

13. Freitas ALM, Chaves J, Krummenauer ML, Tomilin BA, Ourique F, et al. (2017) Prevalência do Diagnóstico de DPOC em pacientes internados com cardiopatia isquêmica em um hospital universitário no interior do estado do Rio Grande do Sul. R Epidemiol Control Infec 7: 14-19.

14. González-Castillo J, Martín-Sánchez FJ, Llinares $P$, Menéndez R, Mujal A, et al. (2014) Guidelines for the management of community-acquired pneumonia in the elderly patient. Rev Esp Quim 27: 69-86.

15. Mihailoff M, Deb S, Lee JA, Lynn J (2017) The effects of multiple chronic conditions on adult patient readmissions and hospital finances: A Management Case Study. Inquiry 54: $1-6$

16. Kenealy TW, Parsons MJ, Rouse AP, Doughty RN, Sheridan NF, et al. (2015) Telecare for diabetes, CHF or COPD: Effect on quality of life, hospital use and costs. A randomised controlled trial and qualitative evaluation. PLoS One 10: e0116188.

17. Labella AM, Merel SE, Phelan EA (2011) Ten ways to improve the care of elderly patients in the hospital. J Hosp Med 6: 351-357.

18. Kim YS, Han SH, Hwang JH, Park JM, Lee J, et al. (2017) Development of the Korean framework for senior-friendly hospitals: A Delphi study. BMC Health Serv Res 17: 528.

19. Hartgerink JM, Cramm JM, Bakker TJ, Mackenbach JP, Nieboer AP (2015) The importance of older patients' experiences with care delivery for their quality of life after hospitalization. BMC Health Serv Res 15: 311.

20. Michaëlis C, Kristiansen M, Norredam M (2015) Quality of life and coping strategies among immigrant women living with pain in Denmark: A qualitative study. BMJ Open 5: e008075.
21. Björnsdóttir SV, Arnljótsdóttir M, Tómasson G, Triebel J, Valdimarsdóttir UA (2016) Health-related quality of life improvements among women with chronic pain: Comparison of two multidisciplinary interventions. Disabil Rehabil 38: 828-836.

22. Kwak Y, Kim Y (2017) Health-related quality of life and mental health of elderly by occupational status. Iran $\mathrm{J}$ Public Health 46: 1028-1037.

23. Célia Nunes MR, L Ribeiro RC, FPL Rosado LE, Franceschini SC (2009) Influência das características sociodemográficas e epidemiológicas na capacidade funcional de idosos residentes em Ubá, Minas Gerais. Rev Bras Fisioter 13.

24. Lubetkin El, Jia H (2017) Burden of disease associated with lower levels of income among US adults aged 65 and older. BMJ Open 7: e013720.

25. Castaldelli-Maia JM, da Silva NR, Campos MR, Moura HF, Zabert G, et al. (2017) Implementing evidence-based smoking cessation treatment in psychosocial care units (CAPS) in Brazil. Int J Soc Psychiatry 63: 669-673.

26. Pavão AL, Werneck GL, Campos MR (2013) Self-rated health and the association with social and demographic factors, health behavior, and morbidity: A national health survey. Cad Saude Publica 29: 723-734.

27. Feemster LC, Cooke CR, Rubenfeld GD, Hough CL, Ehlenbach WJ, et al. (2015) The influence of hospitalization or intensive care unit admission on declines in healthrelated quality of life. Ann Am Thorac Soc 12: 35-45.

28. Lu Y, Nyunt MS, Gwee X, Feng L, Feng L, et al. (2012) Life event stress and chronic obstructive pulmonary disease (COPD): Associations with mental well-being and quality of life in a population-based study. BMJ Open 2: e001674.

29. Virtuoso Junior J, Guerra RO (2011) Functional incapacity among low-income elderly women. Ciênc Saúde Coletiva 16: 2541-2548. 